\title{
Numerical Simulation of Fluid Transport along Parallel Vanes for Vane Type Propellant Tanks
}

\author{
Baotang Zhuang ${ }^{1,2} \cdot$ Yong $^{\mathrm{Li}^{1}} \cdot$ Jintao Liu ${ }^{1} \cdot$ Wei Rui $^{3}$
}

Received: 26 April 2019 / Accepted: 24 September 2019 / Published online: 15 November 2019

(C) Springer Nature B.V. 2019

\begin{abstract}
Fuel tanks are a core component in satellites that manage the propellant. This study numerically analyzed the fluid transport with parallel guide vanes in a vane type surface tension tank. Flow3D was used to simulate fluid transport in microgravity in a scale model with $15 \%$ liquid filling rate with comparisons to experimental data. Then, the simulations were used to compare the leading edge climbing speed for various working conditions and the liquid volume below a specified cross section for various liquid filling rates, various numbers of vanes. The results show that the liquid climbing process on the guide plate in the plate tank can be divided into the liquid level repositioning stage after the gravitational force is suddenly removed and the stable fluid transport stage. Throughout the entire capillary flow stage, the liquid leading edge climbing rate is not related to the filling rate of the number of vanes and the fluid transport efficiency of a single guide vane is independent of the total number of vanes.
\end{abstract}

Keywords Microgravity $\cdot$ Vane type tank $\cdot$ Fluid flow $\cdot$ Propellant management $\cdot$ Surface tension driven flow

\section{Introduction}

The core component of a satellite fuel tank is the Propellant Management Device (PMD). Satellite fuel tanks can be divided into various types according to the PMD working mode as spin tanks, diaphragm tanks, and surface tension tanks. Surface tension tanks are the most common type of large satellite propellant tank. Surface tension tanks can be divided into the first representative type of surface tension tank and the second representative type. Dominick and Tegart (1994) described the Fluid Acquisition and Resupply Experiment (FARE) which was a Shuttle middeck-mounted experiment to demonstrate techniques for handing liquids in zero gravity for operations such as refueling spacecraft in orbit. Meyer et al. (2014) addressed the basic requirements for propellant slosh, settling, and short-term storage/pressure

Baotang Zhuang

bt_zhuang@126.com

$1 \quad$ Beijing Institute of Control Engineering, Beijing 100190, China

2 Beijing Engineering Research Center of Efficient and Green Aerospace Propulsion Technology, Beijing 100190, China

3 Institute of Mechanics, Chinese Academy of Sciences, Beijing 100190, China control. The three-dimensional capillary interfaces in spacecraft propellant management devices were analyzed with the Surface Evolver code by Collicott and Weislogel (2013). The Orbital Express demonstration program was a satelliteservicing mission that included fluid transfer using a surface tension type PMD (Dipprey and Rotenberger 2013). Wei(2013) numerically simulated liquid sloshing in a vane type PMD with and without anti-sloshing baffles in microgravity. Zhuang et al. (2014) experimentally investigated the fluid storage and transportation in a refillable propellant reservoir using a microgravity drop tower. Collicott and Weislogel (2002) observed liquid-vapor interface in a transparent PMD in the Vented Tank Resupply Experiment (VTRE). The first representative surface tension tanks had screen-type structures which could provide propellant flow during acceleration and in microgravity as validated in extrusion efficiency tests in a normal gravity environment. However, the sieve structure was expensive, unreliable and heavy. The second representative type of surface tension tank mainly used vane-type structures with the angle between vanes or the small gap between a vane and the tank wall used to transfer and store liquid, which made the devices more reliable and less complex than the screen-type structures, but they could not be tested on the ground.

The literature has many studies of propellant transport in microgravity. For example, Li et al. (2012) studied 


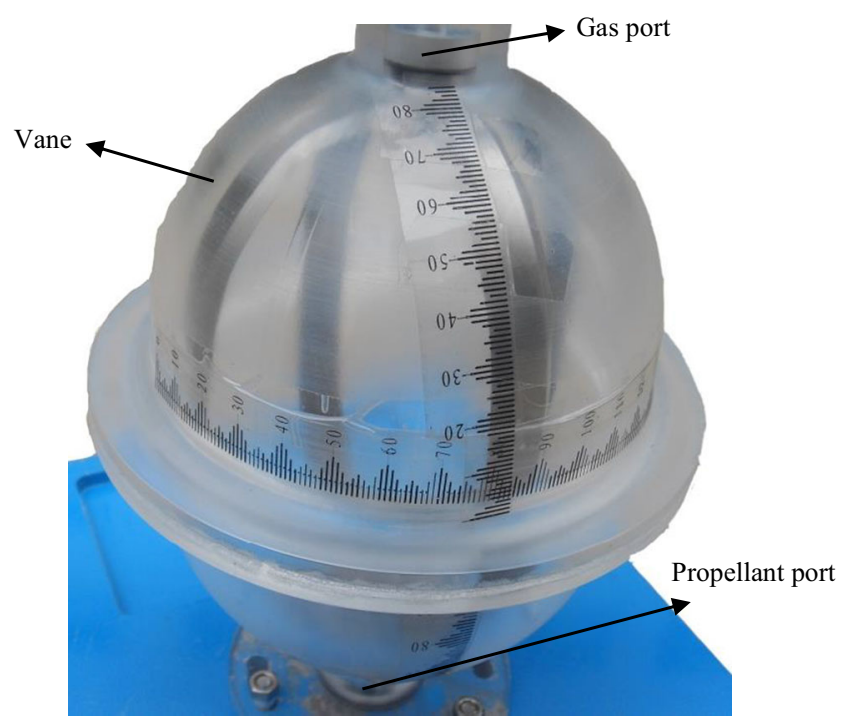

Fig. 1 Propellant tank

liquid sloshing in a vane type tank in microgravity. Lapilli et al. (2015) studied the microgravity fluid dynamics in a sphere slosh experiment. Li et al. (2017) numerically analyzed the fluid mechanics of capillary flow in microgravity in a fan-shaped asymmetric interior corner. They analyzed the effect of the contact angle on the rise height in the corner and developed a Concus-Finn condition for the capillary flow in the corner. Han and Chen (2019) studied the effect of the geometry on merged droplet formation in a double T-junction microchannel using three-dimensional numerical simulations using the level-set method. The fluid motion in a spherical tank in microgravity conditions

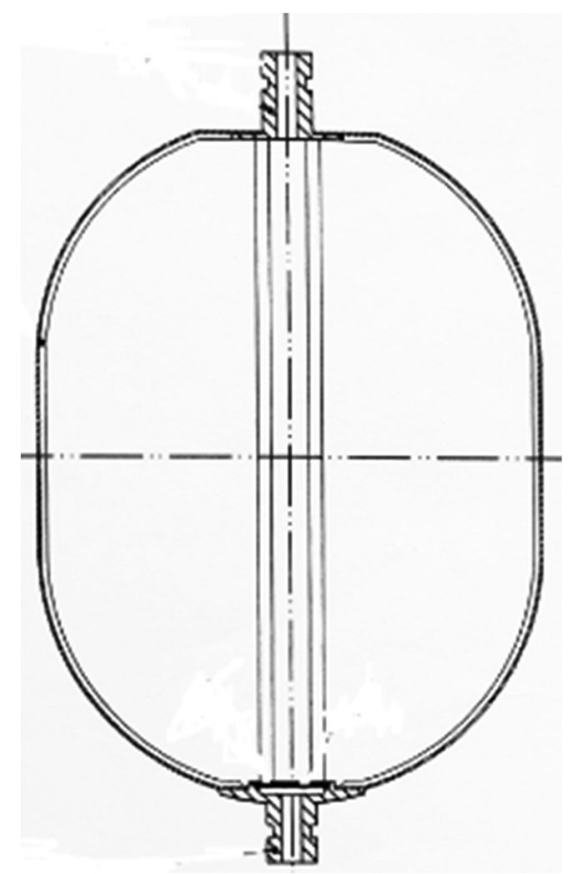

Fig. 2 Vane configuration

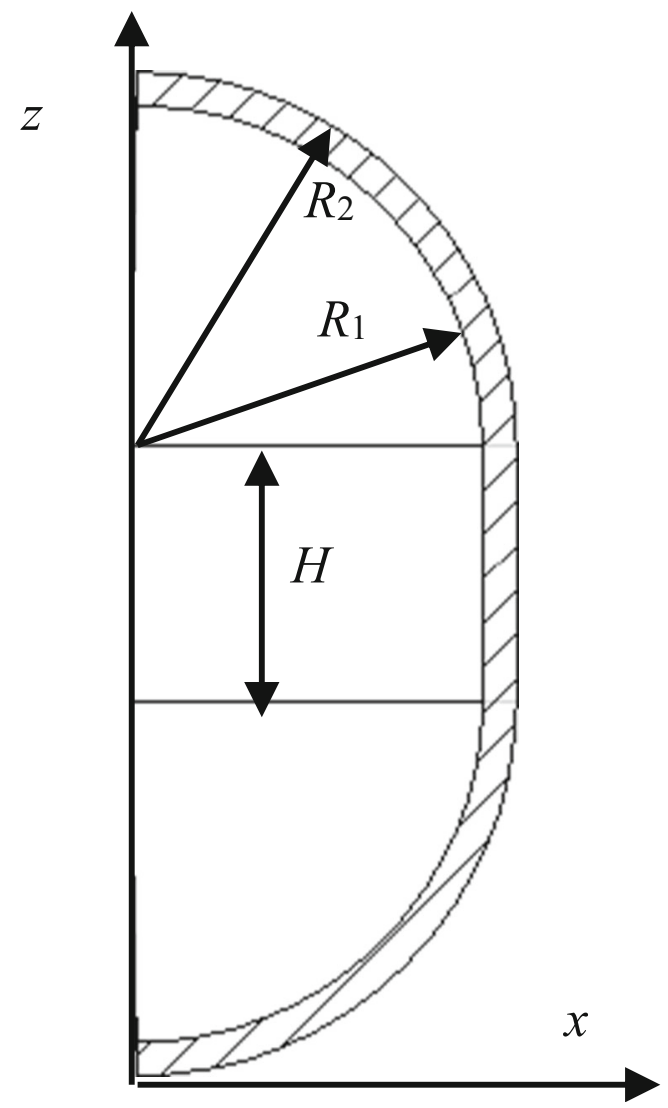

Fig. 3 Tank geometry

was investigated by Dalmon et al. (2019) through comparisons of data from the FLUIDICS experiment in the ISS with Direct Numerical Simulations of the two-phase flow. Gaulke et al. (2015) numerically studied capillary transport of a liquid between parallel perforated plates in microgravity with various geometries to show how the capillary transport capability correlated with the perforation diameter and plate porosity. Bolleddula et al. (2010) reviewed capillary rise flows and drop tower investigations and developed an analytical solution for flows along planar interior edges. Kang et al. (2016) described a microgravity experiment investigating thermocapillary convection in an open cylindrical annular pool to be done on the SJ-10 satellite. Ground experiment results showed the temperature oscillations, surface oscillations, and flow patterns. Li et al. (2015) presented the governing equation for capillary driven flow in a cylindrical interior corner with an approximate analytical solution and showed that capillary driven flow in cylindrical interior corners satisfied the Concus-Finn condition in microgravity. The also presented a relationship for the variation of the liquid front position with time which was then compared with the results of drop tower experiments and numerical simulations. Zhang et al. (2018) experimentally investigated 


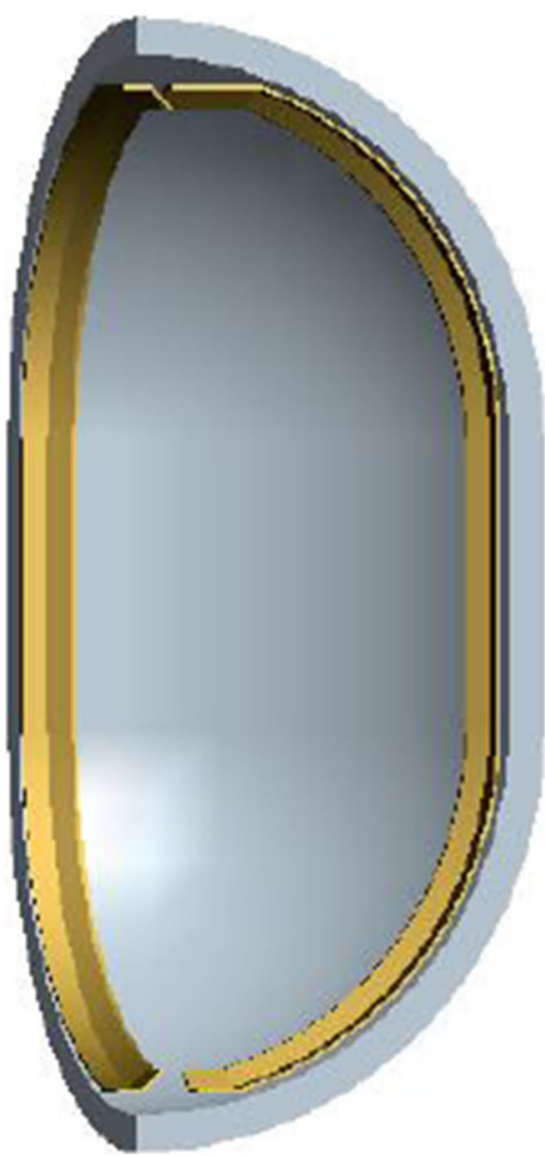

Fig. 4 Assembly drawing with 4 vanes

the migration and interaction of two axisymmetric drops in a vertical temperature gradient on the ground with a discussion of the influence of the dimensionless initial distance between the drop centers on the drop migration.

$\mathrm{Hu}$ et al. $(2015,2016)$ studied the hydrodynamic behavior in microgravity. Chen et al. (2018) studied the propellant transport in a vane type tank during on-orbit refueling using a VOF two-phase flow model to predict the fluid behavior in microgravity and the flow characteristics during refueling. Various new types of propellant tanks have been developed in recent years, such as the green propellant tank and the cryogenic tank, with studies of the propellant management in these tanks. Mulkey et al. (2016) developed an LMP$103 \mathrm{~S}$ propellant-compatible titanium rolling diaphragm tank

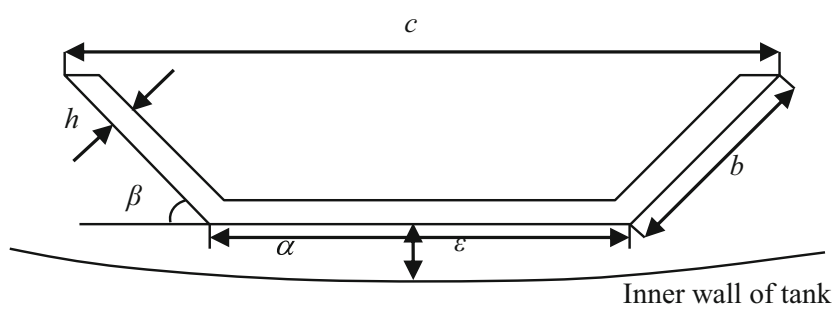

Fig. 5 Vane middle cross section for use in the Green Propellant Loading Demonstration(GPLD) flight vessel. Masuda et al. (2014) designed and tested a composite propellant tank. Conomos et al. (2017) designed and tested a 10 in. diameter titanium propellant tank with a Rolling Metal Diaphragm (RMD) the propellant expulsion device which was then used in a flight. Benkelman et al. (2017) developed an affordable, lightweight composite liquid oxygen propellant tank for applications up to $100 \mathrm{~km}$. Lapilli et al. (2015) investigated the diaphragm behavior in a diaphragm propellant tank. Lenahen et al. (2012) modeled oscillating liquid propellant in a propellant tank. At present, most Chinese satellites still use screen-type tanks with few studies of the propellant distribution and transport in vane type tanks. Therefore, this study numerically analyzes the propellant transport in a vane type tank with comparison to experimental data to provide a model for engineering applications.

\section{Propellant Tank and Vane Configuration}

The shape of the vane propellant tank in this study is shown in Fig. 1. The tank consists of two hemispherical shells and a cylindrical section. The inner and outer diameters of the sphere and the cylindrical section are all the same. The tank has four symmetric metal vanes which are connected to the gas and propellant ports. The vane design is shown in Fig. 2. The small gap between the vane and the tank wall is the liquid transport channel.

\section{Computational Model}

The propellant motion in the tank was modeled using Flow3D. The 1:8 scale model had an inner diameter $R_{1}=$ $51.25 \mathrm{~mm}$, outer diameter $R_{2}=56.25 \mathrm{~mm}$, and cylindrical segment height $H=38.26 \mathrm{~mm}$ in Fig. 3 .

The drop tower in the National Microgravity Laboratory was $100 \mathrm{~m}$ high with an effective height of $80 \mathrm{~m}$. Therefore, the effective microgravity test time in this facility was $3 \mathrm{~s}$ and the residual acceleration was $5^{*} 10^{-3} g_{0}$. In these conditions, the flow in the tank was symmetrical along the vanes. Therefore, the simulations only modeled $1 / 4$ of the tank as shown in Fig. 4 with symmetry boundary conditions. The mesh was a uniform mesh block.

Figure 5 shows the vane dimensions. The flow channel is based on the dimensionless flow channel ratio $\mathrm{m}=\varepsilon / \alpha$. The vane width is $\alpha$ and the clearance between the midpoint of the vane and the tank wall is $\varepsilon$. Anhydrous ethanol was used as the medium with the constant properties listed in Table 1. The fluid was assumed to be an incompressible Newtonian fluid. The fluid was assumed to be laminar with consideration of the effect of viscosity. 
Table 1 Physical parameters for an anhydrous ethanol tank at $20^{\circ} \mathrm{C}$

\begin{tabular}{lllllll}
\hline Name & Molecular formula & $\rho\left(\mathrm{kg} / \mathrm{m}^{3}\right)$ & $\sigma(\mathrm{N} / \mathrm{m})$ & $\mu(\mathrm{Pa} \cdot \mathrm{s})$ & Contact angle (PMMA) & Grade \\
\hline Anhydrous ethanol & $\mathrm{C}_{2} \mathrm{H}_{5} \mathrm{OH}$ & 789 & 0.02246 & 0.01096 & 0 & analytical purity \\
\hline
\end{tabular}

\section{Governing Equations}

FL0W-3D uses the FAVOR finite difference model based on a structured grid and the true three-step volume tracking numerical method (Tru-VOF method) to accurately predict the free surface flow. The model in this study is based on the following equations:

$\nabla \cdot v=0$

$\frac{\partial v}{\partial t}+v \cdot \nabla \cdot v=-\frac{1}{\rho} \nabla p+\frac{\mu}{\rho} \Delta v+g-f$

$\frac{\partial F}{\partial t}+v \cdot \nabla F=0$

Where $v$ is the fluid velocity vector, $g$ is the gravitational acceleration vector, $f$ is the surface tension of the gas-liquid interface, $p$ is the pressure, $\rho$ is the fluid density, $\mu$ is the dynamic viscosity, and $F=F(x, y, z)$ is the volume function of the fluid in the calculation region which ranges from 0 to 1 . For each element, $F=1$ means that the element is filled with fluid while $F=0$ means that the element is empty and $F$ between 0 and 1 means that the element is partially filled with fluid.

\section{Results and Analysis}

\section{Comparison of Numerical and Experimental Results}

The simulation accuracy was verified using data for a microgravity drop tower experiment with $15 \%$ liquid filling with 4 vanes, vane widths, $\alpha$, of $7.5 \mathrm{~mm}$, and vane angles of $\beta=45$ degrees.

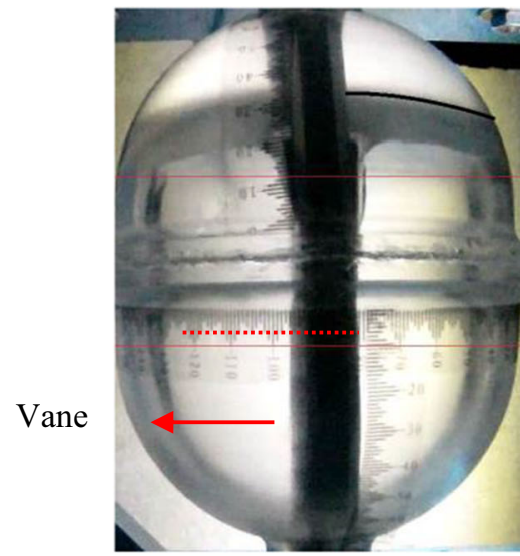

$t=0.5 \mathrm{~s}$

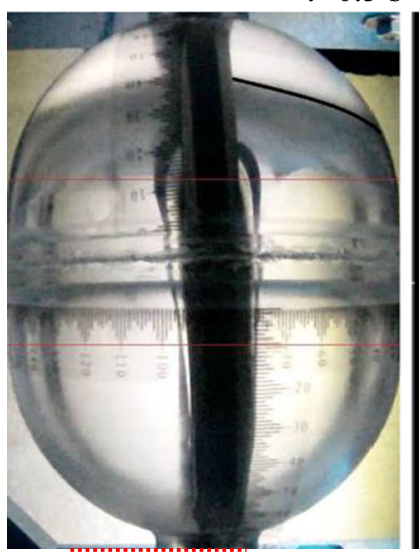

$t=1.5 \mathrm{~s}$
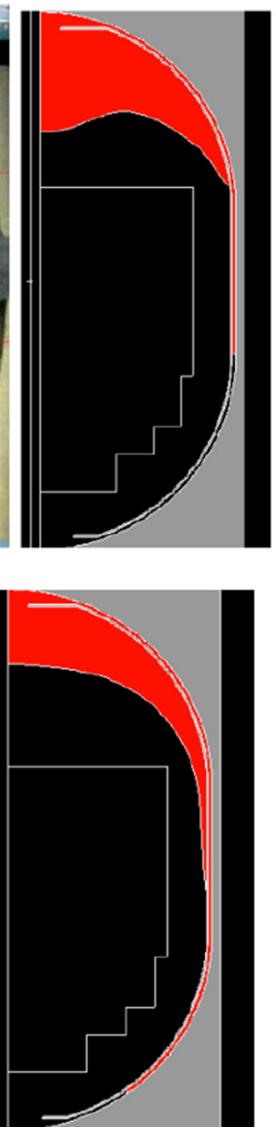
1

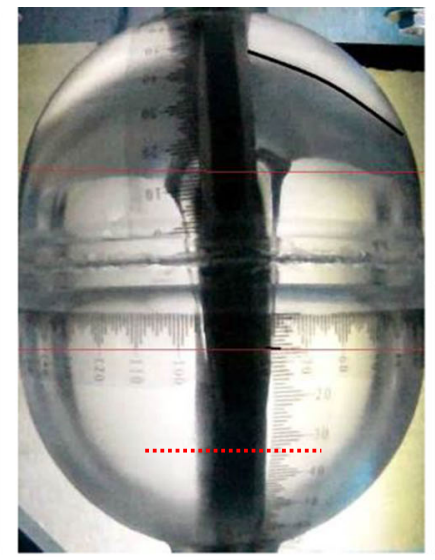

$t=1 \mathrm{~s}$

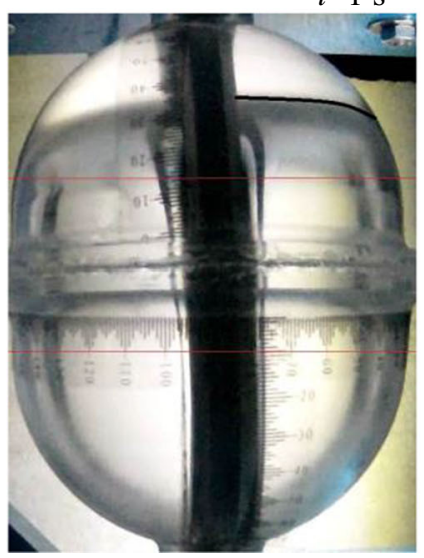

$t=2.5 \mathrm{~s}$
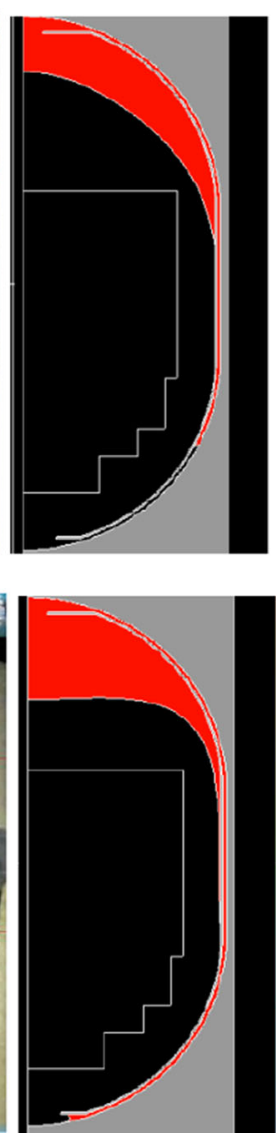

Fig. 6 Predicted and measured liquid interface positions with $15 \%$ filling 


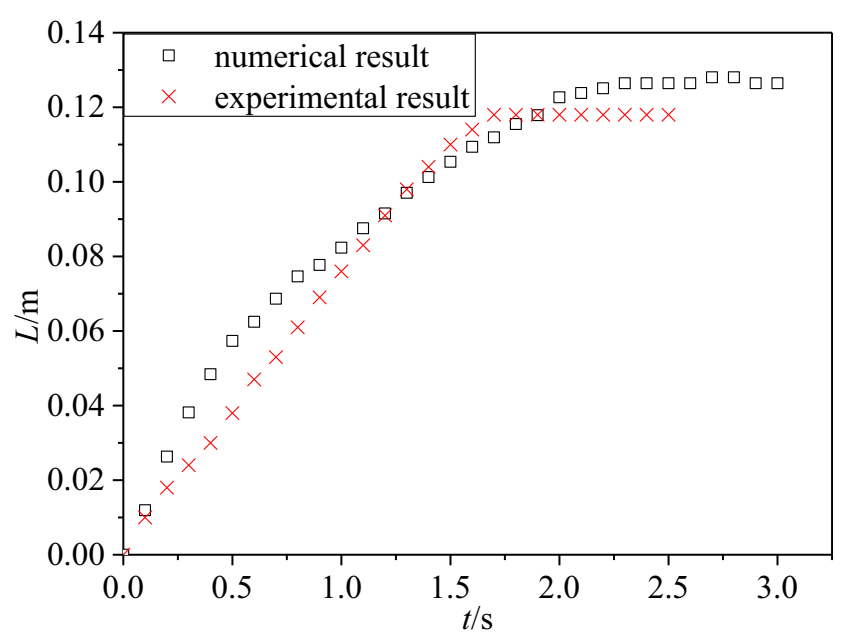

Fig. 7 Comparison of the predicted and measured leading edge locations with $15 \%$ filling

Fig. 8 Liquid distributions at various times, $5 \%$ filling
The experiment was conducted in the drop tower facility of the National Microgravity Laboratory of China. The microgravity level was $5^{*} 10^{-3} g_{0}$ and the microgravity time was $3.5 \mathrm{~s}$. The video recording rate was 30 fps illuminated by an LED with the liquid leading edge position (climbing arc length), L, determined by a transparent scale attached to the outer wall. Figure $6 \mathrm{com}-$ pares shows typical measured and predicted liquid level changes during the experiment. In the initial stage, the liquid covers the tank gas port. The acceleration is along the positive z-axis direction and the liquid flows along the negative $\mathrm{z}$-axis direction. The dotted line in the figure represents the liquid front position and the solid line represents the cylindrical wall. The simulation results in Fig. 6 show that as the microgravity flow begins, the liquid surface in the pool is convex downward and the liquid surface is wavy. Then, the liquid surface fluctuates and the liquid forms a concave surface at the gas port. After $1 \mathrm{~s}$, the liquid level is lowest at the gas port and then rebounds downward. After
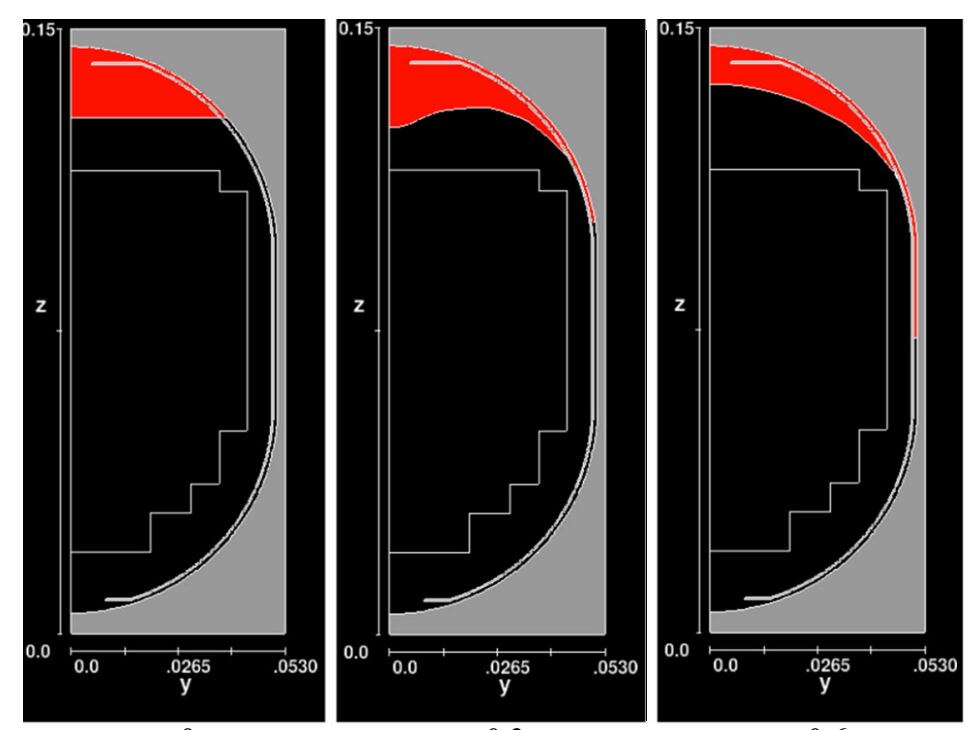

$t=0.3 \mathrm{~s}$

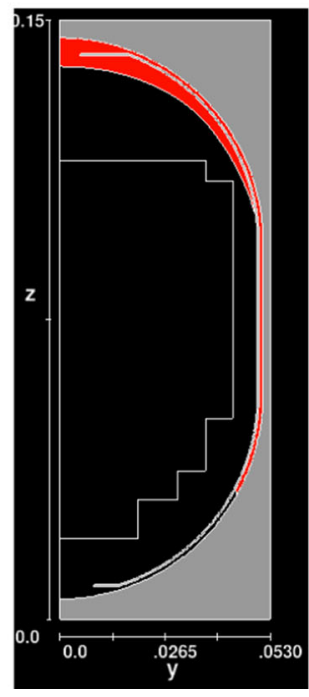

$t=1.5 \mathrm{~s}$

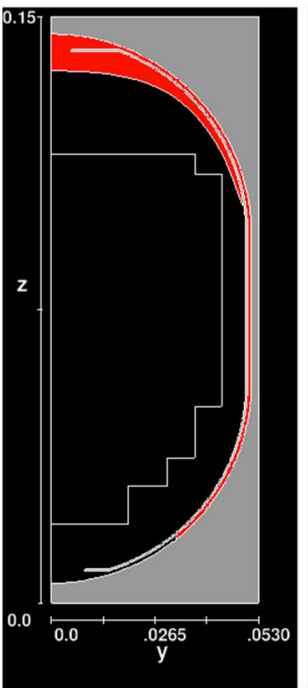

$t=2 \mathrm{~s}$

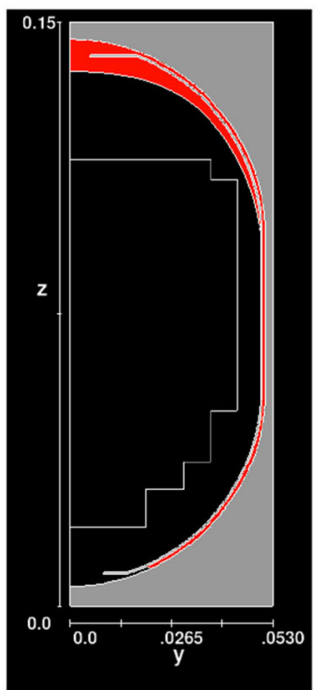

$t=2.5 \mathrm{~s}$

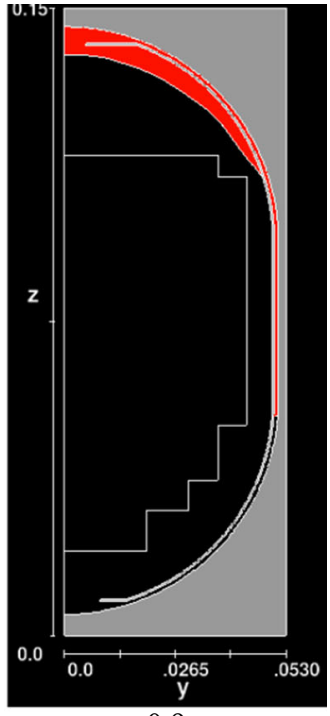

$t=0.9 \mathrm{~s}$

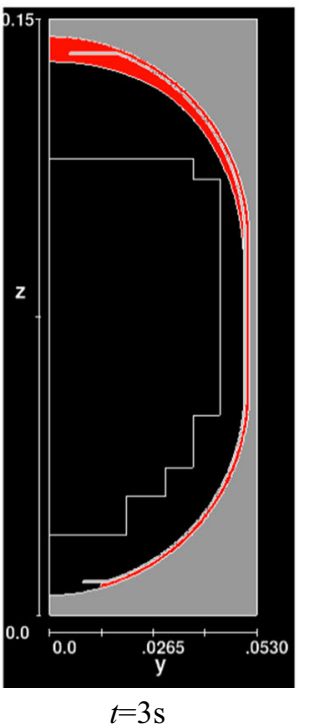


Fig. 9 Liquid distributions at various times, $15 \%$ filling

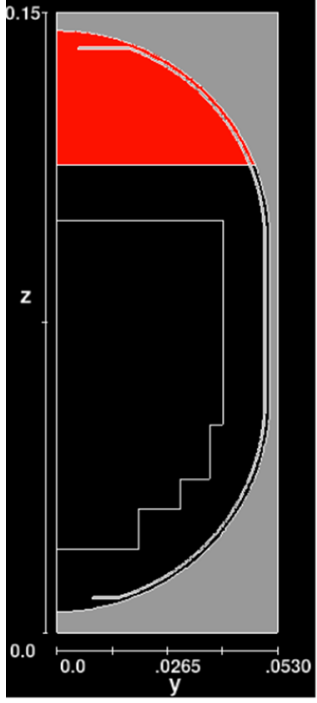

$t=0 \mathrm{~s}$

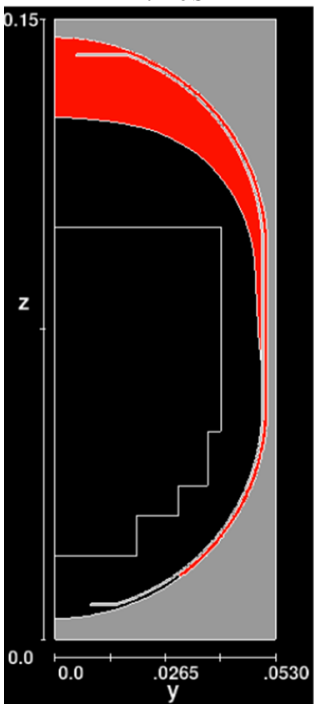

$\mathrm{t}=1.5 \mathrm{~s}$

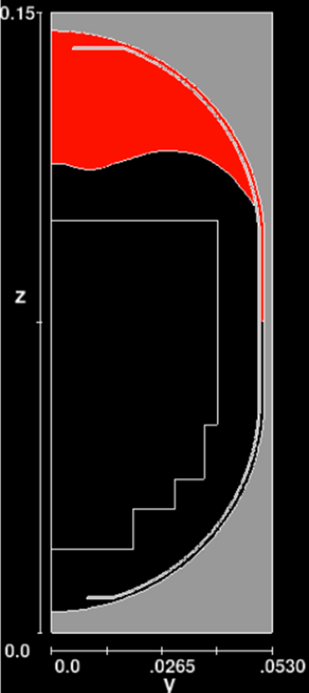

$t=0.3 \mathrm{~s}$

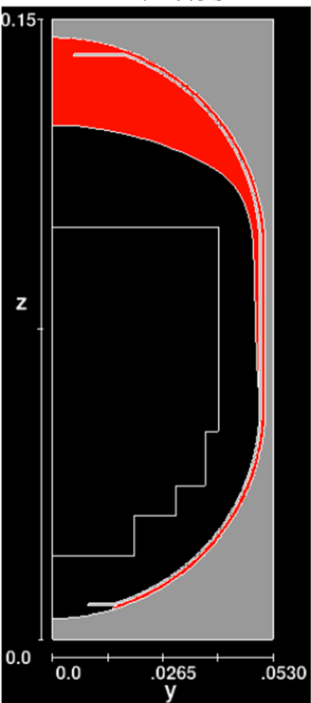

$\mathrm{t}=2 \mathrm{~s}$

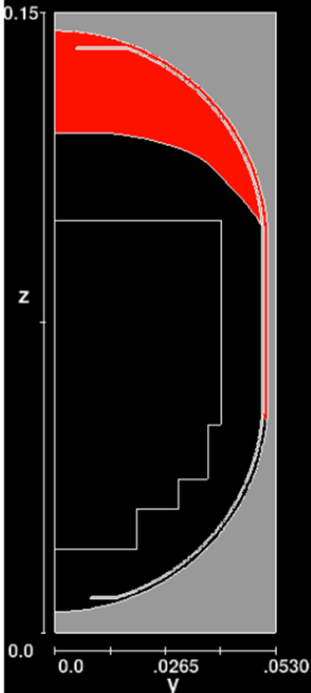

$t=0.6 \mathrm{~s}$

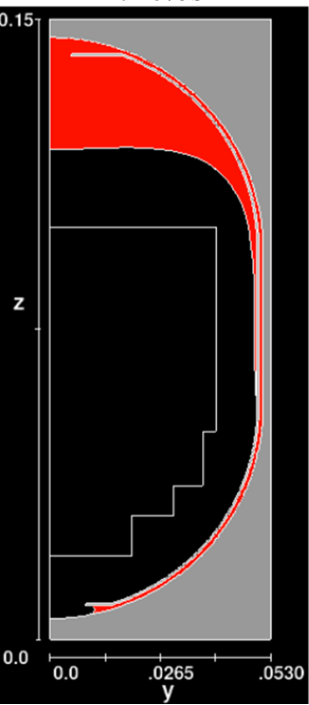

$\mathrm{t}=2.5 \mathrm{~s}$

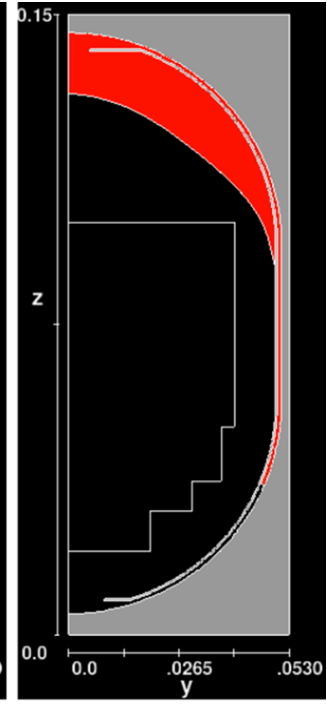

$t=0.9 \mathrm{~s}$

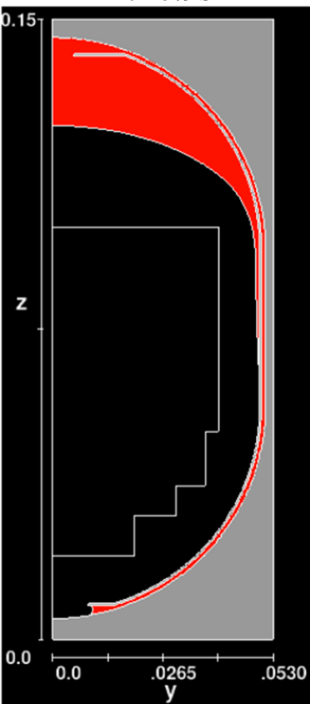

$\mathrm{t}=3 \mathrm{~s}$
$2.5 \mathrm{~s}$, the liquid level is basically level and with a meniscus near the wall. At this time, the liquid leading edge has reached the highest point on the vane. The results show that the numerical and experimental results are consistent. The black strip in the experimental results is a metal guide plate which is not transparent. The numerical accuracy is further illustrated by the comparison of the predicted and measured leading edge positions, L, plotted versus time in Fig. 7.

The results in Fig. 7 show that the liquid edge no longer moves after $1.7 \mathrm{~s}$ because of the shooting angle. The change in the surface height exceeds the shooting range after $1.6 \mathrm{~s}$ at which time the liquid basically reaches the top of the tank. The predicted heights agree well with the experimental data which verifies the accuracy of the numerical simulations. Flow3D was then used to study the effects of various filling rates, numbers of vanes, clearance, $\varepsilon$, vane width, $\alpha$, and angle, $\beta$, on the flow dynamics.

\section{Effect of Filling Rate on the Fluid Transport}

The guide vane is usually used to transport liquid propellant to the liquid port of the tank. In this design, the tank is composed of two hemispheres and a cylindrical section. As the liquid flows out, the liquid volume in the tank changes. Therefore, this study analyzes the fluid transport rate with the guide vanes in the tank with smaller amounts of liquid in the tank. The bottom of the liquid was assumed to reach the gas port for the worst case conditions assuming that the initial liquid interface was horizontal with initial liquid levels of 5\%, 15\%, 25\% and $35 \%$. All the cases had 4 vanes, a vane width $\alpha=7.5 \mathrm{~mm}$, a gap width $\varepsilon=1 \mathrm{~mm}$, and angle $\beta=45^{\circ}$ with absolute ethanol as the working medium.

Figures 8, 9, 10 and 11 show the liquid distributions in the tank with 4 vanes and a vane width $\alpha=7.5 \mathrm{~mm}$ for the 4 filling levels. The figures show that the four filling rates lead 
Fig. 10 Liquid distributions at various times, $25 \%$ filling
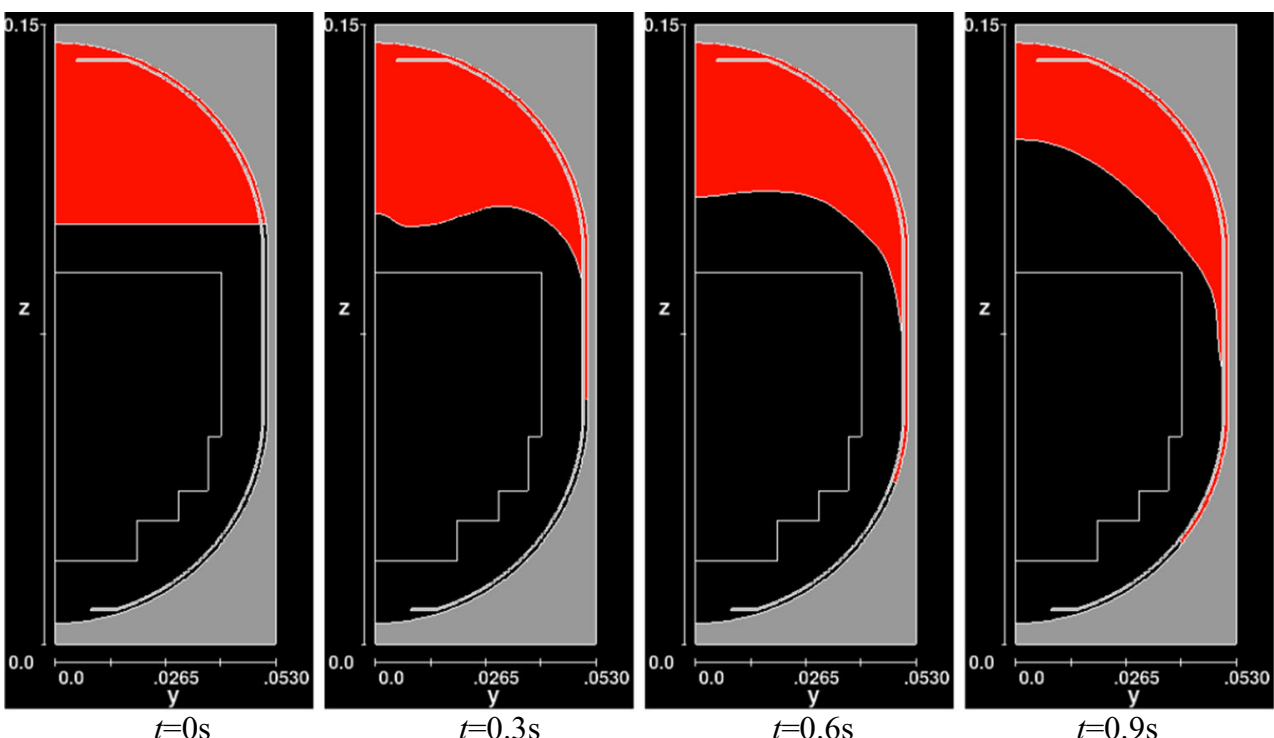

$t=0.6 \mathrm{~s}$

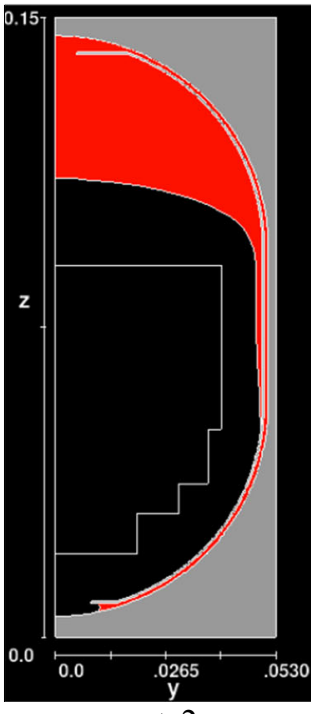

$t=2 \mathrm{~s}$

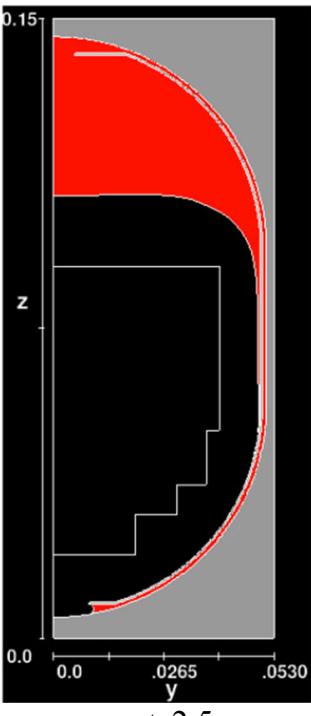

$t=2.5 \mathrm{~s}$

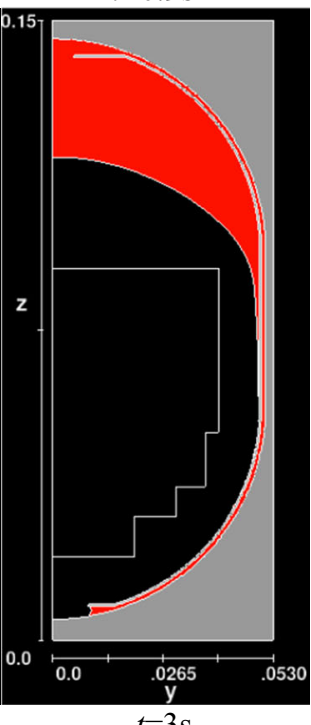

to similar liquid level changes. As the microgravity flow begins, the liquid climbs along the gap between the guide vane and the wall. The liquid level in the tank becomes wavy and liquid level moves back and forth. Figure 12 shows the leading edge locations, L, for the various filling rates with the initial liquid level as the zero position. The liquid leading edge positions for all 4 initial heights coincide as the front climbs to the top of the vane.

Stange et al. (2003) pointed out that capillary flows in cylindrical vessels can be divided into several stages. In each stage, the capillary flow is driven by the interaction of the surface tension and the various flow resistances. The first stage balances the inertia force and the capillary force. The liquid front position is then proportional to $t^{2}$. The second stage is proportional to $t$. The third stage balances the viscous force and the capillary force. Here, $L$ is proportional to $t^{1 / 2}$. This stage is called the LucasWashburn stage. Generally speaking, the capillary flow fully developed in the third stage, which is the most important stage. Therefore, the straight line slope in this region represents the liquid front climbing rate by fitting $L^{2}$ versus time. The results in Fig. 13 show that the curve fit slopes for the various filling rates are very similar, that is, the liquid climbing rate is not a function of the filling rate or the liquid level.

\section{Influence of the Number of Vanes on the Fluid Transport}

The worst case with very little liquid, the liquid is mainly transported by the guide vane. One PMD tank design principle is that they have a small number of simple structures, so the influence of the number of vanes on the fluid transport is important. Here, the fluid transport was analyzed for 4, 6 and 8 vanes with a liquid filling rate of $15 \%$, a vane width $\alpha=7.5 \mathrm{~mm}$, a gap width $\varepsilon=1 \mathrm{~mm}$, and angle $\beta=45^{\circ}$ with 
Fig. 11 Liquid distributions at various times, $35 \%$ filling
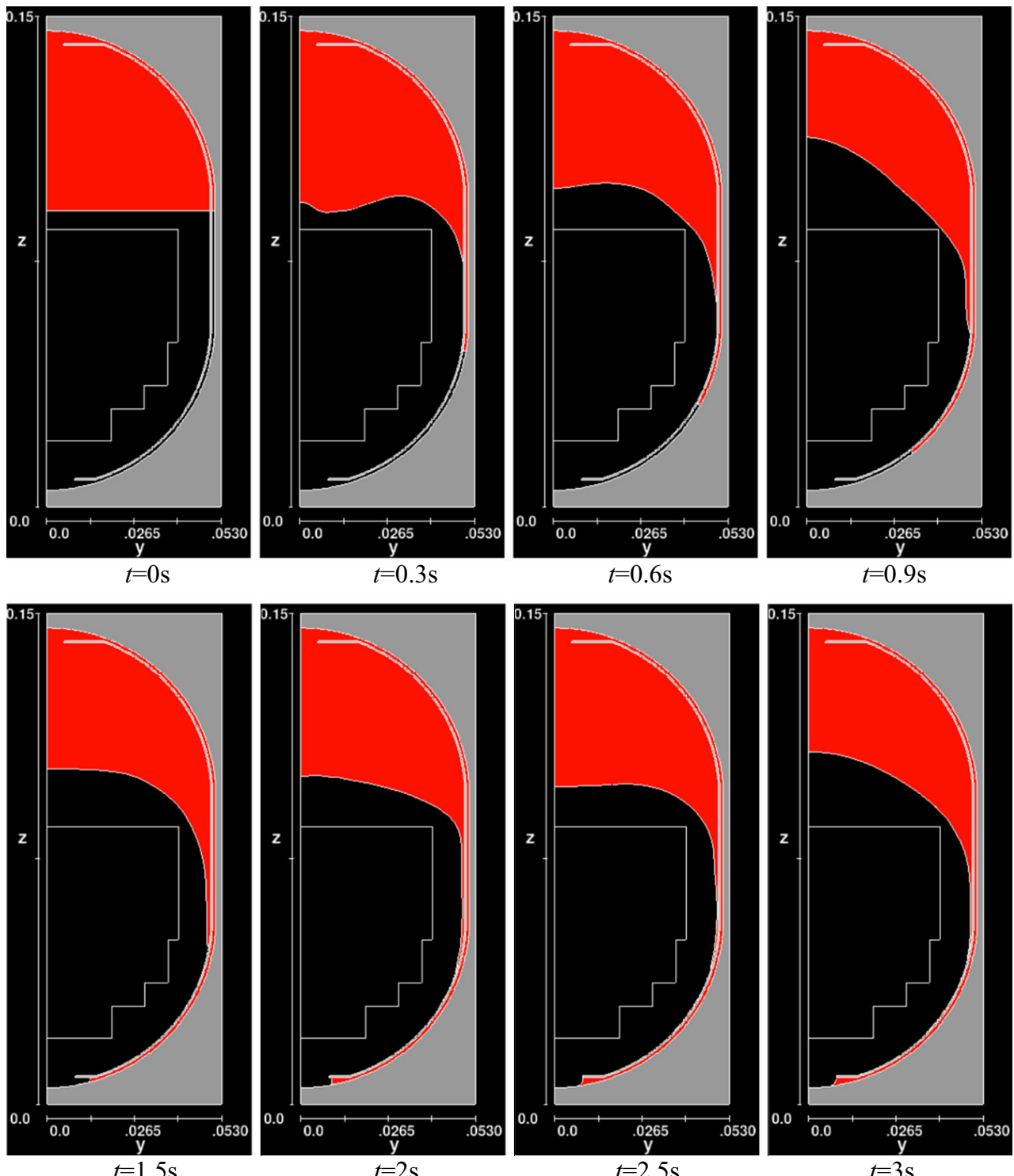

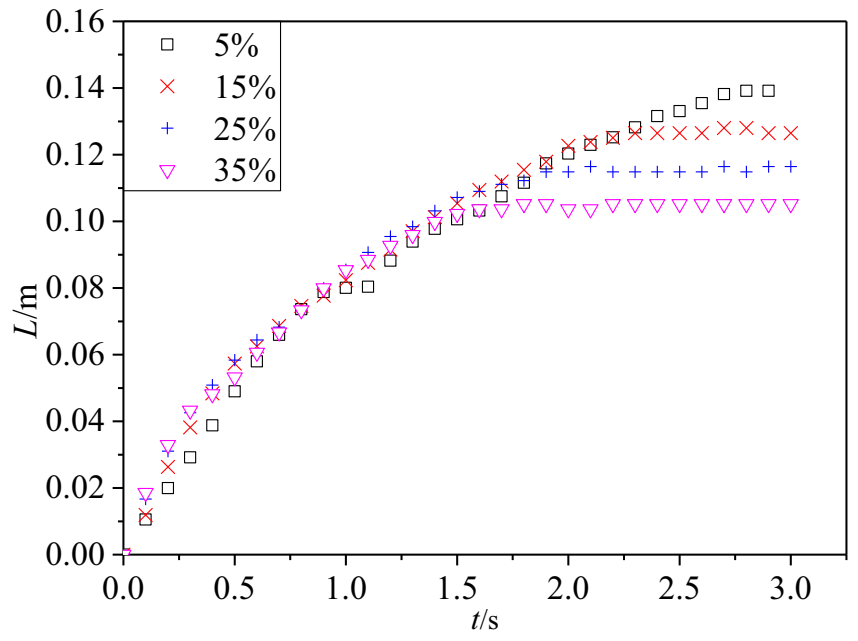

Fig. 12 Leading edge locations for various filling rates

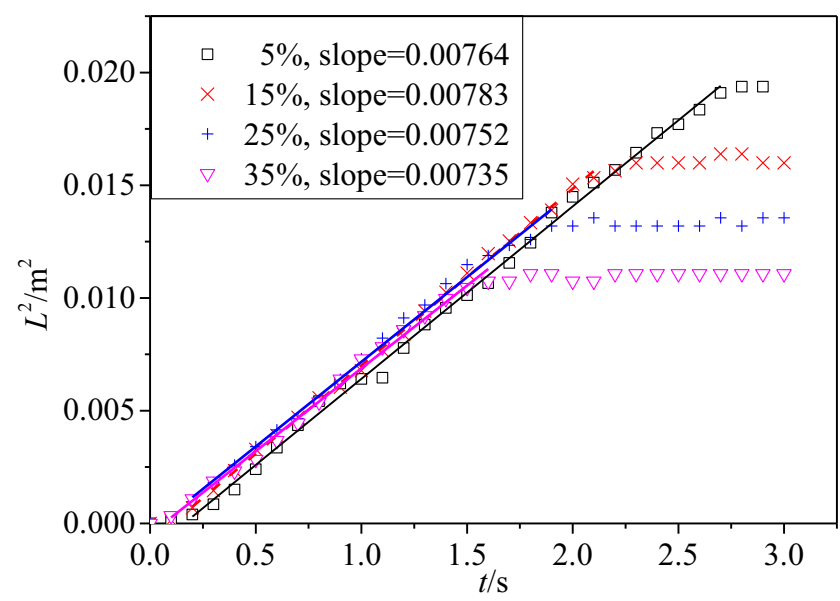

Fig. 13 Correlations of the square of the leading edge location as a function of time for various filling rates 
Fig. 14 Cross-sections of various models

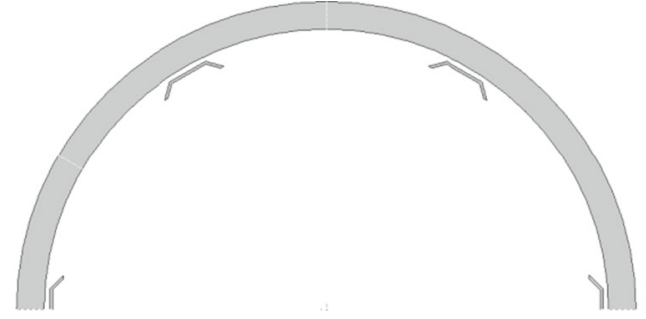

(a) Cross-section of 6 vane model

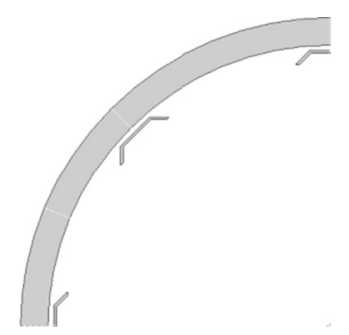

(b) Cross-section of 8 vane model absolute ethanol as the working medium. A half model with 6 vanes is shown in Fig. 14(a). The quarter model used for 8 vanes is shown in Fig. 14(b). The boundary conditions at the symmetric surfaces in both geometries were both symmetrical.

The position of the liquid leading edge is plotted in Fig. 15 for the 4, 6 and 8 vanes which shows that the leading edge position is exactly the same for all three cases. Thus, for a $15 \%$ filling rate, the leading edge climbing rate is independent of the number of vanes because the liquid surfaces formed between each single vane and the tank wall do not interfere with each other and the liquid surface curvature does not change with more vanes.

The fluid transport with various numbers of vanes is also illustrated by plotting the variation of the liquid volume on each vane with time in Fig. 16. The liquid level first increases, then decreases and then increases again because the liquid near the initial location oscillates back and forth near the wall. The front climbs up the wall for the first $1.5 \mathrm{~s}$ and then begins to fall after $1.5 \mathrm{~s}$. Figure 9 also reflects this phenomenon. $Z=$ $85.8 \mathrm{~mm}$ is used as the zero level, which is referred to as crosssection $z_{0}$ here. Figure 17 shows the variation of the liquid volume with time below cross section $z_{0}$. The slope of the

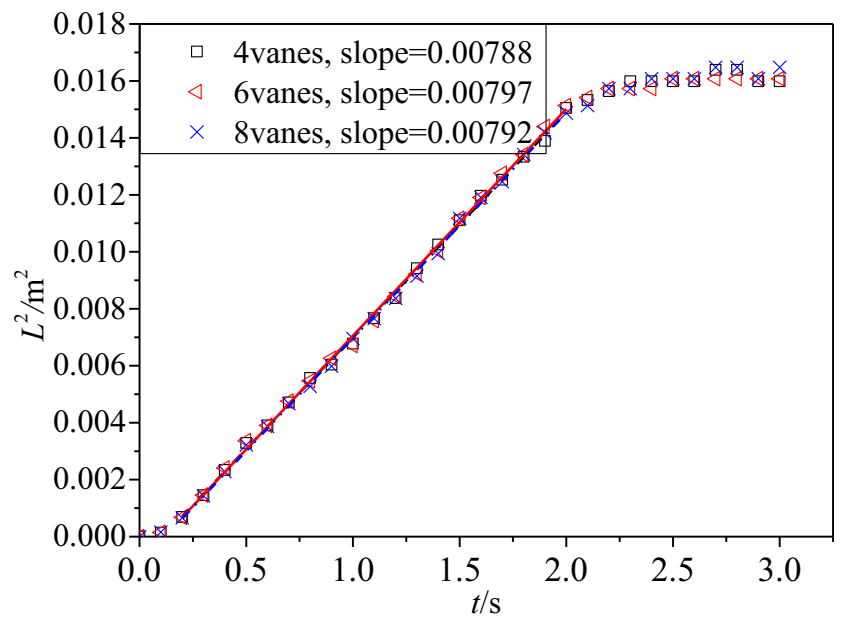

Fig. 15 Correlation of the leading edge location as a function of time for various numbers of vanes curve fit shows that the liquid volume conveyed by the guide vane is proportional to the number of vanes. Thus, the transport capacity of 8 vanes is about twice that of 4 vanes while that of 6 vanes is about 1.5 times that of 4 vanes. Therefore, for a $15 \%$ filling rate, the liquid transport rate is proportional to the number of vanes. The results also show that increasing the number of vanes does not change the transport efficiency of each vane.

\section{Conclusions}

- The process of liquid climbing on a guide vane in a vane tank can be divided into the liquid level repositioning stage after microgravity is imposed on the system and the stable fluid transport stage along the guide vanes. $L \sim t$ during the repositioning stage and $L \sim t^{1 / 2}$ during the stable fluid transport stage.

- During the stable fluid transport stage, the climbing rate of the liquid front is independent of the filling rate and the number of vanes.

- The fluid transport efficiency of a single guide vane is independent of the number of vanes.

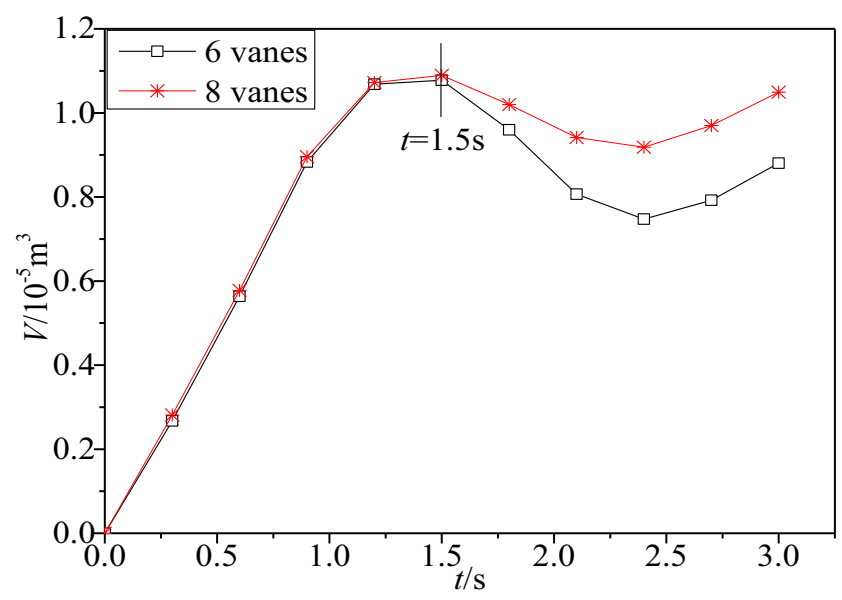

Fig. 16 Liquid volume on each vane for various numbers of vanes 


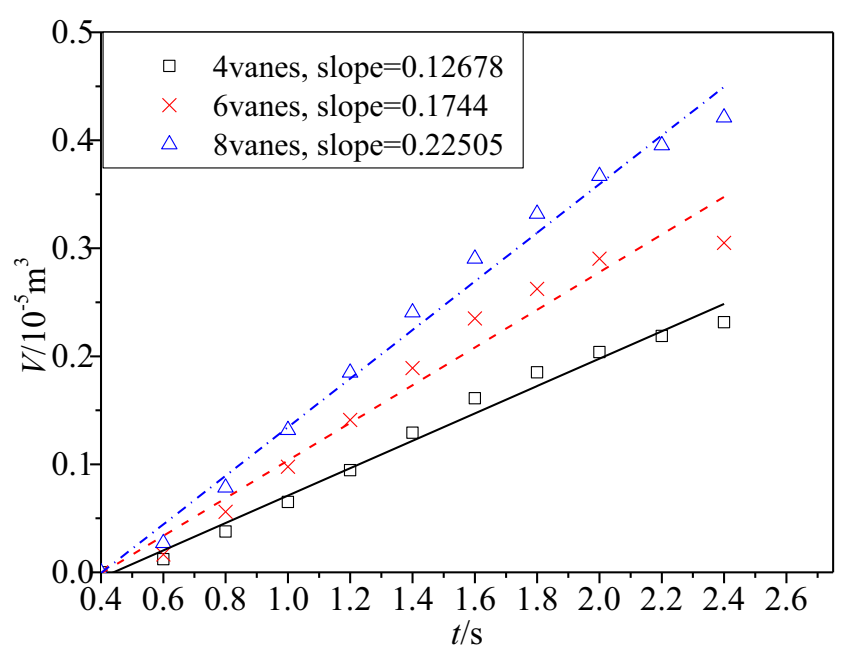

Fig. 17 Liquid volume below section $z_{0}$ for various numbers of vanes

Acknowledgements This research was financially supported by the National Natural Science Foundation of China (Grant No. 51776017).

\section{References}

Alexis, D., Mathieu, L., Sébastien, T.: Comparison between the FLUIDICS experiment and direct numerical simulations of fluid sloshing in spherical tanks under microgravity conditions. Microgravity Sci. Technol. 31(1), 123-138 (2019)

Baotang, Z., Yong, L., Hailin, P.: Experimental investigation on fluidstorage characteristic of propellant refillable reservoir in microgravity environment. Aerosp. Control Appl. 40, 27-30 (2014)

Brian L, Adrien B, Grace P.: A Comparison Investigation of Experimental and Computational Fuel Slosh Models Utilizing Diaphragm-Implemented Spacecraft Propellant Tanks. 53rd AIAA/ASME/ASCE/AHS/ASC Structures, Structural Dynamics and Materials Conference, 20th AI, AIAA 2012-1885, Hawaii (2012a)

Brian L, Adrien B, Sathya G. A.: Computational Investigation for Determining the Natural Frequencies and Damping Effects of Diaphragm-Implemented Spacecraft Propellant Tanks. 53rd AIAA/ASME/ASCE/AHS/ASC Structures, Structural Dynamics and Materials Conference, 20th AI, AIAA 2012-1886, Hawaii (2012b)

Collicott S.H., Weislogel M.: Modeling of the operation of the VTRE propellant management device. In 38th AIAA/SAE/ASME/ASEE joint propulsion conference, Indianapolis (2002)

Collicott S., Weislogel M.: Modeling of the operation of the VTRE propellant management device. AIAA/ASME/SAE/ASEE Joint Propulsion Conference \& Exhibit, 559-567 (2013)

Daniel, A.B., Yongkang, C., Ben, S.: Compound capillary flows in complex containers: drop tower test results. Microgravity Sci. Technol. 22(4), 475-485 (2010)

Diana, G., Michael, E.D.: CFD simulation of capillary transport of liquid between parallel perforated plates using Flow3D. Microgravity Sci. Technol. 27(4), 261-271 (2015)

Dipprey N., Rotenberger S.: Orbital express propellant resupply servicing. AIAA/ASME/SAE/ASEE Joint Propulsion Conference and Exhibit (2013)

Dominick S., Tegart J.: Orbital test results of a vaned liquid acquisition device. AIAA, 94-3027 (1994)
Gabriel L, Daniel K, Hector G.: Results of microgravity fluid dynamics captured with the spheres-slosh experiment. 66th international Astronautical congress, Israel (2015a)

Gabriel L, Hector G, Daniel K.: Characterization of Elastomeric Diaphragm Motion within a Spacecraft Propellant Tank. 51st AIAA/SAE/ASEE Joint Propulsion Conference, The U.S (2015b)

Harry C, Christopher G. A, Jacqueline Y.: Development of 10 inch Diameter Titanium Rolling Metal Diaphragm Tank for Green Propellant. AIAA Propulsion and Energy Forum, 53rd AIAA/SAE/ASEE Joint Propulsion Conference, The U.S (2017)

Henry W.M, Joseph T.M, Caitlin E.B.: Green Propellant Loading Demonstration at U.S. Range. Propulsion and Energy Forum, 52nd AIAA/SAE/ASEE Joint Propulsion Conference, UT (2016)

Ideo M, Tadashi M, Kazuki M.: Development of New Composite Propellant Tank for Satellites. Propulsion and Energy Forum, 50th AIAA/ASME/SAE/ASEE Joint Propulsion Conference, The U.S (2014)

Jinghao, L., Xiaoqian, C., Yiyong, H.: The review of the interior corner flow research in microgravity. Procedia Eng. 31, 331-336 (2012)

Lei C, Jintao L, Xinrong L.: Numerical simulation of the vane type tank and system on-orbit refueling process. IOP Conf. Series: J. Phys.: Conf. Series 1074, 012060 (2018)

Meyer, M.L., Chato, D.J., Plachta, D.W.: Mastering cryogenic propellants. J. Aerosp. Eng. 26, 343-351 (2014)

Neil B., Russel B, Alex F.: Design and Manufacture of Composite Liquid Oxygen Propellant Tank for University Rocket. AIAA SPACE Forum, The U.S (2017)

Parallel Perforated Plates using flow3D. Microgravity Science and Technology, 27(4), 261-271(2015)

Qi H, Xianwu L.: Research on fluid transmission performance of propellant acquisition vane microgravity environment. Proceedings of the ASME-JSME-KSME 2015 joint fluids engineering conference, Korea (2015)

Qi H, Yong L, Hailin P.: Numerical analysis and experiment research on fluid orbital performance of vane type propellant management device. IOP Conf. Series: Mater. Sci. Eng. 72, 042042 (2015)

Qi, K., Li, D., Li, Z.: Thermocapillary convection experiment facility of an open cylindrical annuli for SJ-10 satellite. Microgravity Sci. Technol. 28(2), 123-132 (2016a)

Qi H, Yong L, Jintao L.: Research on liquid sloshing performance in vane type tank under microgravity. IOP Conf. Series: Mater. Sci. Eng. 129,012016 (2016b)

Shuoting, Z., Li, D., Qi, K.: Experimental research on Thermocapillarybuoyancy migration interaction of axisymmetric two drops by using digital holographic interferometry. Microgravity Sci. Technol. 30(3), 183-193 (2018)

Stange, M., Dreyer, M., Rath, H.J.: Capillary driven flow in circular cylindrical tubes. Phys. Fluids. 9, 2597-2601 (2003)

WenBo H, Xueye C.: Effect of Geometry Configuration on the Merged Droplet Formation in a Double T-Junction. Microgravity Science and Technology, pp 1-10 (2019)

Yongqiang, L., Mingzhu, H., Ling, L.: Study of capillary driven flow in an interior corner of Rounded Wall under microgravity. Microgravity Sci. Technol. 27(3), 193-205 (2015)

Yongqiang, L., Wenhui, C., Ling, L.: Numerical simulation of capillary flow in fan-shaped asymmetric interior corner under microgravity. Microgravity Sci. Technol. 29(1-2), 65-79 (2017)

Yuexing W.: Research on the Flow in the Process of the Propellant Management in a Spacecraft Tank under Microgravity. National University of Defense Technology, (2013)

Publisher's Note Springer Nature remains neutral with regard to jurisdictional claims in published maps and institutional affiliations. 